\title{
Cognitive Behavior Therapy and Mindfulness Training in the Treatment of Adults Who Stutter
}

\author{
Sanjeev Kumar Gupta ${ }^{1}$, Yashodharakumar G. Y. ${ }^{2}$, Vasudha H. $\mathrm{H}^{3}$
}

\section{ABSTRACT}

Introduction: Stuttering is a developmental speech disorder with multiple etiological factors. Cognitive behavior therapy (CBT) has shown effectiveness in reducing anxiety symptoms and dysfluent speech in adults who stutter (AWS). So we planned to study the comparative efficacy of CBT and CBT combined with mindfulness training (MT) in AWS. Aim: The aim of this preliminary study was to examine and compare the efficacy of CBT and CBT combined with MT in reducing anxiety symptoms, and dysfluent speech and increasing communication attitude, quality of life, self-esteem and speech fluency in AWS. Method and Materials: A matched two group pretest and posttest interventional design was employed. The sample consisted of ten adults with the diagnosis of stuttering (ICD-10, 1992) who were randomly allotted to Group One (CBT; $N=5)$ and Group Two (CBT+MT; N=5). The therapeutic program included 15-20 sessions of one hour each. Statistical Analysis: Obtained data were analyzed using the Wilcoxon Sign Rank Test for within the group, before and after intervention comparison and Mann Whitney U Test for between group comparisons. Results: Significant difference in both CBT group and $\mathrm{CBT}+\mathrm{MT}$ group is observed in the area of communication attitude $(\mathrm{U}=1.00, \mathrm{p}<0.05)$. Conclusion: The findings of the study show that $\mathrm{CBT}$ and $\mathrm{CBT}+\mathrm{MT}$ are effective in the treatment of AWS, but CBT+MT is more effective than CBT alone.

Keywords: Anxiety, Cognitive Behavior Therapy, Mindfulness meditation, Stuttering.

Stuttering occurs in approximately 1\% of the general population (Bloodstein, 1995) and in 5 \% of primary school children (Onyeizugbo, 2011). It is more common in men than in women by a ratio of 4:1. (Onyeizugbo, 2011). Stuttering is defined as speech that is characterized by frequent

\footnotetext{
${ }^{1}$ Clinical Psychologist, Department of Clinical Psychology, All India Institute of Speech and Hearing, Mysuru, Karnataka, India

${ }^{2}$ Clinical Psychologist Grade-II, Department of Clinical Psychology, All India Institute of Speech and Hearing, Mysuru, Karnataka, India

${ }^{3}$ M.Phil. Trainee, Department of Clinical Psychology, National Institute of Mental Health and Neurosciences, Bengaluru, Karnataka, India

*Responding Author

(c) 2016 I S Gupta, Y Yashodharakumar, H Vasudha; licensee IJIP. This is an Open Access Research distributed under the terms of the Creative Commons Attribution License (http://creativecommons.org/licenses/by/2.0), which permits unrestricted use, distribution, and reproduction in any Medium, provided the original work is properly cited.
} 


\section{Cognitive Behavior Therapy and Mindfulness Training in the Treatment of Adults Who Stutter}

repetition or prolongation of sounds or syllables or words, or by frequent hesitation or pauses that disrupt the rhythmic flow of speech (WHO, 1993). Therefore the core behaviors of stuttering are repetitions, prolongations and blocks (Guitar, 2006).

Cognitive Behavior Therapy (CBT) is one of the major orientations of psychotherapy (Roth \& Fonagy, 2005). It is mainly concerned with understanding the role of cognitions, or the personal meaning that the individuals assign to events and on working within this domain in order to achieve cognitive as well as behavioral change. It is structured, focused on specific problems, time-limited and educative, encouraging individuals to understand their difficulties better (Beck, 1995). CBT is used with adults experiencing high levels of trait, state, and social anxiety related to stuttering and speaking (Hancock K \& Craig, 1998; Ezrati-Vinacour \& Levin, 2004). It has been reported that approximately $50 \%$ of adults who stutter (AWS) may have significantly high levels of social anxiety (Kraaimaat, Vanryckeghem, \& Van Dam-Baggen, 2002; Menzies et al., 2008). The goal of CBT in AWS is to reduce social avoidance and anxiety (Craig \& Tran, 2006; Menzies, Onslow, Packman, \& O’Brian, 2009). For example, Reddy, Sharma, and Shivashankar (2010) observed reduction of stuttering, anxiety, dysfunctional cognitions and improvement in quality of life after implementing 16-18 sessions of CBT.

The term 'mindfulness' is an English translation of the Pali word Sati. Pali was the language of Buddhist psychology 2,500 years ago, and mindfulness is the core teaching of this tradition. The word Sati indicates awareness, attention, and remembering (Germer, 2005). Mindfulness has been defined as "the awareness that emerges through paying attention on purpose, in the present moment, and nonjudgementally to the unfolding of experience moment by moment" (KabatZinn, 2003). In psychotherapy, the concept of mindfulness is defined as "an awareness of present experience with acceptance” (Germer, 2005). Mindfulness-based interventions include Mindfulness-Based Stress Reduction (MBSR) (Kabat-Zinn, 1994), Mindfulness-Based Cognitive Therapy (MBCT)(Segal, Williams, \& Teasdale, 2002), Acceptance and Commitment Therapy (Hayes, Luoma, Bond, Masuda, \& Lillis, 2006) and Dialectical Behavior Therapy (Linehan, 1993). Mindfulness-based therapies have shown effectiveness in the reduction of depression and anxiety symptoms in clinical population and unpleasant affect and psychological stress in nonclinical population (Bohlmeijer, Prenger, Taal, \& Cuijpers, 2010; Grossman, Niemann, Schmidt, $\&$ Walach, 2004).

Research studies show that speech therapy treatment for stuttering is available in early childhood (Jones et al., 2005) but stuttering in adults is much less responsive to speech therapy (Craig \& Hancock, 1995). Behavioral speech programs involving speech restructuring are the strongest evidence-based stuttering treatments for AWS (Onslow, Jones, O’Brian, Menzies, \& Packman, 2008). The aim of this study was to compare the efficacy of CBT alone and CBT combined with mindfulness training (MT) for increasing mindfulness, communication attitude, quality of life, self-esteem and speech fluency and reducing level of anxiety, frequency and severity of stuttering in AWS. 


\section{METHOD AND MATERIALS}

\section{Participants}

The sample consisted of ten adults with the diagnosis of stuttering (ICD-10 DCR, F98.5; WHO, 1993), recruited from Out Patient Clinic of Department of Clinical Psychology. Participants with the diagnosis of stuttering, aged between 18 to 35 years, educated at least till class $\mathrm{X}$, and having obtained a minimum total score of 20 on Stuttering Severity Instrument (SSI) (Riley, 1994) were included. Participants with significant medical, psychiatric, neurological disorders as associated conditions, obtaining less than 20 total scores on SSI, and having previous exposure to the cognitive behavioral intervention were excluded. Participants were randomly allotted to the Group One (CBT; N=5) and Group Two (CBT+MT; N=5). All the participants were explained the purpose and procedure of the study, written informed consent was taken and confidentiality was assured as enshrined in the mandate on ethical guidelines followed at the institute (Venkatesan, 2009)

\section{Research Design}

A matched two group pretest and posttest interventional design was employed. Equal number of cases was randomly assigned to $\mathrm{CBT}$ and $\mathrm{CBT}+\mathrm{MT}$ group. Two independent variables are CBT and $\mathrm{CBT}+\mathrm{MT}$ and their effect were observed on dependent variables like mindfulness, communication attitude, quality of life, anxiety, self-esteem, perception of stuttering, and severity of stuttering.

\section{Measures}

Socio-Demographic and Clinical Data Sheet: A Socio-demographic and Clinical Data Sheet was used to obtain the relevant information on the demographic and clinical history.

Toronto Mindfulness Scale (TMS; Lau et Al., 2006): A 13-item state-mindfulness measure that uses a 5 point Likert-type scale from not at all (0) to very much (4). The scale has two sub-scales: Curiosity, 6 items, subscale score ranging from 0-24, and Decentering, 7 items, with a subscale score ranging from 0-28. Cronbach's alphas are reported to range from 0.86 to 0.91 for Curiosity and 0.85 to 0.87 for Decentering (Park, Reilly-Spong \& Gross, 2013).

Modified Erickson Scale of Communication Attitudes (MESCA; Andrews \& Cutler, 1974): MESCA measures communication attitude. This 24- item scale distinguishes the extent to which a stuttering person's communication attitude deviates from normed attitudes. Statements require a true or false answer. The higher the score, the poorer the communication attitude.

WHO Quality of Life-BREF Scale (WHOQoL-BREF; WHOQoL Group, 1998): It consists of 24 items and provides a profile of scores on four dimensions of quality of life: physical health, psychological, social relationships, and the environment. It is available in both selfadministered and interviewer administered forms. Higher scores reflect a better quality of life. 
Beck Anxiety Inventory (BAI; Beck \& Steer, 1993): BAI is a 21-item scale developed to assess the severity of anxiety symptoms. Respondents are asked to rate each item on a 4point scale ranging from 0 (not at all) to 3 (severely, can barely stand it). Ratings are for the past week. Items are summed to obtain total scores ranging from 0 to 63.

Rosenberg's Self-Esteem Scale (RSES; Rosenberg, 1965): A 10-item scale that measures global self-worth by measuring both positive and negative feelings about the self. The scale is believed to be uni-dimensional. All items are answered using a 4-point Likert scale format ranging from strongly agree to strongly disagree. Items 2, 5, 6, 8, 9 are reverse scored. Items are scored as follows: "Strongly Disagree” 1 point, "Disagree” 2 points, "Agree” 3 points, and "Strongly Agree" 4 points. Scores for all ten items are summed up. Higher scores indicate higher self-esteem.

Perceptions of Stuttering Inventory (PSI; Woolf, 1967): The PSI is a 60-item inventory equally divided into three dimensions: (a) Struggle, (b) Avoidance, and (c) Expectancy. For each item, participants indicated how well the described behavior was characteristic of their stuttering. Severity levels for each of the three dimensions according to scores on the PSI are mild (0-7), moderate (8-11), moderate to severe (12-15), and severe (16-20).

Stuttering Severity Instrument-3 (SSI-3; Riley, 1994): It is a measure of stuttering severity and was based on a 20-minutes interview session. The interview was then used to assess the frequency and duration of stuttering and any associated physical concomitants, and these were converted to SSI-3 scores using the specified guidelines. The adult who stutter scored 20 or higher, this score placed between the 12 and 23rd percentile and rated as mild. Higher score reflects higher severity level of stuttering.

\section{Therapeutic Program}

Cognitive Behavior Therapy intervention program included orientation regarding the nature, causes and treatment of stuttering. The 'cognitive-behavioral model' and 'vicious cycle' of stuttering was drawn and discussed with the participants. The cognitive-behavioral model is based upon the assumption that our thoughts and beliefs influence our emotions, physiology, and behavior (Beck, 1995). Negative automatic thoughts were identified and challenged by checking the evidence. They were taught deep breathing and relaxation techniques to control speechrelated anxiety. Cognitive/speech restructuring was incorporated to modify speech-related dysfunctional beliefs. Problem solving technique was introduced to increase their sense of being able to cope up with speech-related difficulties when they arise. They were asked to self-monitor the speech-related anxiety symptoms during communication with strangers and authority persons like teachers and employer and also asked to self-monitor speech-related dysfunctional beliefs and speech-related difficulties if any, and maintain a diary for the same.

Mindfulness Training included sitting mindfulness meditation; awareness about their thoughts, feelings and body; awareness of the present moment; identifying past, present and future thinking; integrating mindfulness and acceptance into daily life (Semple, Lee, \& Miller, 2006). Participants of both the groups were encouraged to generalize controlled fluency in all situations 
and with different listeners inside and outside the clinical setting and also were asked to maintain the improvement through everyday practice and interaction with others.

\section{Procedure}

Patients with stuttering were screened based on inclusion and exclusion criteria. After that they underwent pre assessment individually on various scales, namely, Toronto Mindfulness Scale, Modified Erickson Scale of Communication Attitudes, WHO Quality of Life-BREF Scale, Beck Anxiety Inventory, Rosenberg's Self-Esteem Scale, Perceptions of Stuttering Inventory, and Stuttering Severity Instrument. After pre assessment both group CBT and CBT+MT were subjected to an individual treatment program. The treatment program consisted of 15-20 sessions of CBT or CBT+MT that were held over a period of eight weeks. Two to three sessions were held every week and each session lasted for 60 minutes. After Intervention, they were again rated on same measures. Participants were assigned homework consisting of regular practice at home and maintenance of a diary for the same.

\section{Statistical Analysis}

The collected data as raw scores on respondent ratings were compiled and subjected to statistical analysis by using SPSS statistics for windows, version 17.0 (SPSS Inc, 2008). Obtained data was analyzed using non-parametric statistics, namely, Mann Whitney U Test (for between group comparison) and Wilcoxon Sign Rank Test (for within group comparison).

\section{RESULTS}

In present study, the CBT group consisted of five male patients with a mean age of 20.60 (Standard Deviation; SD+3.36) years, whereas the CBT+MT group consisted of one female and four male patients (total 5 patients) with a mean age of 23.20 (SD+6.61) years. The mean year of formal education was $14.60\left(\mathrm{SD}_{\underline{2}} 2.19\right)$ years for the CBT group and $14.00(\mathrm{SD}+2.73)$ years for the CBT+MT group. The overall comparison between both the group on before and after

intervention scores is shown in table-1. There is significant difference in both CBT group and $\mathrm{CBT}+\mathrm{MT}$ group in all the measures i.e. Mindfulness (TMS; $\mathrm{Z}=-2.807, \mathrm{p}<0.01$ ), communication attitude (MESCA; Z=-2.812, $\mathrm{p}<0.01$ ), quality of life (WHOQOL-BREF; $Z=-2.807, \mathrm{p}<0.01$ ), anxiety (BAI; $\mathrm{Z}=-2.814, \mathrm{p}<0.01$ ), self-esteem (RSES; $\mathrm{Z}=-2.670, \mathrm{p}<0.01$ ), perception of stuttering (PSI; Z=-2.807, $\mathrm{p}<0.01$ ), and severity of stuttering (SSI; Z=-2.805, $\mathrm{p}<0.01)($ Table-1). 
Table 1: Comparison between before and after intervention scores across both groups

\begin{tabular}{|l|l|l|l|l|}
\hline \multirow{2}{*}{ Measures } & \multicolumn{2}{|c|}{ Sessions } & $\begin{array}{l}\text { Wilcoxon } \\
\text { Signed Ranks }\end{array}$ & p \\
\cline { 2 - 5 } & Before & After & -2.807 & $.005^{* *}$ \\
\hline TMS & $23.20 \pm 6.55$ & $33.20 \pm 3.91$ & -2.812 & $.005^{* *}$ \\
\hline MESCA & $15.40 \pm 2.36$ & $10.70 \pm 1.56$ & $.005^{* *}$ \\
\hline WHOQOL-BREF & $81.40 \pm 7.98$ & $93.90 \pm 4.81$ & -2.807 & $.008^{* *}$ \\
\hline RSES & $22.00 \pm 4.00$ & $27.20 \pm 3.36$ & -2.670 & $.005^{* *}$ \\
\hline BAI & $31.10 \pm 5.13$ & $19.50 \pm 4.45$ & -2.814 & $.005^{* *}$ \\
\hline PSI & $37.30 \pm 11.50$ & $26.40 \pm 10.55$ & -2.807 & $.005^{* *}$ \\
\hline SSI & $27.30 \pm 6.13$ & $15.80 \pm 4.13$ & -2.805 & \\
\hline
\end{tabular}

p $<0.05^{*}, \mathrm{p}<0.01^{* *}$; TMS: Toronto Mindfulness Scale; MESCA: Modified Erickson Scale of Communication Attitudes; WHOQOL-BREF: WHO Quality of Life-BREF; RSES: Rosenberg SelfEsteem Scale; BAI: Beck Anxiety Inventory; PSI: Perceptions of Stuttering Inventory; SSI: Stuttering Severity instrument

Table-2 is showing the comparison between CBT group and CBT+MT group on before and after intervention. Significant difference in both CBT group and CBT+MT group is observed in the area of communication attitude (MESCA; $\mathrm{U}=1.00, \mathrm{p}<0.05$ ). It indicates CBT+MT group is more effective in the improvement of communication attitude in AWS in comparison to CBT alone (Table-2).

Table 2: Comparison between Cognitive Behavior Therapy group and Cognitive Behavior Therapy Combined with Mindfulness Training group on before and after intervention

\begin{tabular}{|c|c|c|c|c|c|c|}
\hline \multirow[b]{2}{*}{ Measures } & \multicolumn{2}{|l|}{ Mean Gain } & \multicolumn{2}{|c|}{ Mean Rank } & \multirow{2}{*}{$\begin{array}{l}\text { Mann } \\
\text { Whitney } \\
\text { U }\end{array}$} & \multirow[b]{2}{*}{$\mathbf{p}$} \\
\hline & $\begin{array}{l}\text { CBT } \\
(\mathbf{n}=5)\end{array}$ & $\begin{array}{l}\text { CBT+MT } \\
(\mathbf{n}=5)\end{array}$ & $\begin{array}{l}\text { CBT } \\
(n=5)\end{array}$ & $\begin{array}{l}\text { CBT+MT } \\
(\mathrm{n}=5)\end{array}$ & & \\
\hline TMS & $7.40 \pm 6.66$ & $12.60 \pm 1.52$ & 4.70 & 6.30 & 8.50 & .421 \\
\hline MESCA & $2.80 \pm 1.48$ & $6.60 \pm 1.51$ & 3.20 & 7.80 & 1.00 & $.016^{*}$ \\
\hline $\begin{array}{l}\text { WHOQOL- } \\
\text { BREF }\end{array}$ & $14.40 \pm 6.06$ & $10.60 \pm 3.78$ & 6.40 & 4.60 & 8.00 & .421 \\
\hline RSES & $4.20 \pm 3.76$ & $6.20 \pm 1.48$ & 4.30 & 6.70 & 6.50 & .222 \\
\hline BAI & $11.80 \pm 2.68$ & $11.40 \pm 3.71$ & 6.00 & 5.00 & 10.00 & .690 \\
\hline PSI & $12.20 \pm 7.62$ & $9.60 \pm 4.82$ & 5.80 & 5.20 & 11.00 & .841 \\
\hline SSI & $12.20 \pm 5.44$ & $10.80 \pm 3.42$ & 5.70 & 5.30 & 11.50 & .841 \\
\hline
\end{tabular}


p<0.05*, p<0.01**; TMS: Toronto Mindfulness Scale; MESCA: Modified Erickson Scale of Communication Attitudes; WHOQOL-BREF: WHO Quality of Life-BREF; RSES: Rosenberg SelfEsteem Scale; BAI: Beck Anxiety Inventory; PSI: Perceptions of Stuttering Inventory; SSI: Stuttering Severity Instrument

\section{DISCUSSION}

The present study was conducted to examine the comparative efficacy of CBT and CBT+MT in the treatment of AWS. The study shows that both CBT and CBT+MT group improved significantly on the measures of mindfulness, communication attitude, quality of life, anxiety and dysfluent speech. The study also reports that CBT+MT group is more effective in the improvement of communication attitude in AWS in comparison to CBT alone. The finding of this study is in line with the studies where a reduction of stuttering, anxiety symptoms and improvement in self-esteem, quality of life, and communication attitude were shown after implementing 16-18 sessions of CBT as well as MBCT (Reddy et al., 2010; Gupta, 2015). The result of the study is consistent with the finding of De Veer, Brouwers, Evers, and Tomic (2009), they examined the psychological impact of the MBSR program on persons who stutter and showed that immediately after the eight-week MBSR program as well as four weeks later, participating persons who stutter suffered less from stress and anxiety about speech situations. However, they were not significantly more confident in their ability to retain fluency in speech situations than those in the waiting list. On the other hand, CBT intervention was associated with significant and sustained improvements in psychological functioning but did not improve fluency (Menzies et al., 2008).

In sum, the findings of the study support the use of the CBT+MT program over CBT alone spread over 15-20 sessions of around 60 minutes duration each for bringing positive changes in measures of anxiety, speech dysfluency, communication attitude, mindfulness, self-esteem, and quality of life in AWS. Thus, CBT+MT program can be used for the long-term treatment of AWS. This program is cost-effective in terms of time and can be conducted in a group setting. A small sample size is the major limitation of this study. Further empirical researches are needed with larger sample size using double blind procedure, control group and follow up to test the efficacy of CBT+MT for the treatment of AWS.

\section{REFERENCES}

Andrews, G., \& Cutler, J. (1974). Stuttering therapy: The relation between changes in symptom level and attitudes. Journal of Speech and Hearing Disorders, 39(3), 312-319.

Beck, A. T., \& Steer, R. A. (1993). Manual for the Beck anxiety inventory. San Antonio, TX: Psychological Corporation.

Beck, J. S. (1995). Cognitive therapy: Basics and beyond. London: Guilford Press.

Bloodstein, O. (1995). A handbook on stuttering (5th ed.). San Diego, CA: Singular Publishing Group.

Bohlmeijer, E., Prenger, R., Taal, E., \& Cuijpers, P. (2010). The effects of mindfulness-based stress reduction therapy on mental health of adults with a chronic medical disease: A meta-analysis. Journal of Psychosomatic Research, 68(6), 539-544. 


\section{Cognitive Behavior Therapy and Mindfulness Training in the Treatment of Adults Who Stutter}

Craig, A. R., \& Hancock, K. (1995). Self-reported factors related to relapse following treatment for stuttering. Australian Journal of Human Communication Disorders, 23(1), 48-60.

Craig, A., \& Tran, Y. (2006). Fear of speaking: Chronic anxiety and stammering. Advances in Psychiatric Treatment, 12(1), 63-68.

De Veer, S., Brouwers, A., Evers, W., \& Tomic, W. (2009). A pilot study of the psychological impact of the mindfulness-based stress reduction program on persons who stutter. European Psychotherapy, 9, 39-56.

Ezrati-Vinacour, R., \& Levin, I. (2004). The relationship between anxiety and stuttering: A multidimensional approach. Journal of Fluency Disorders, 29(2), 135-148.

Germer, C. K. (2005). Mindfulness what is it? What does it matter? In C. K. Germer, R. D. Siegel, \& P. R. Fulton (Eds.). Mindfulness and Psychotherapy (pp. 5-7). New York: Guildford Press.

Grossman, P., Niemann, L., Schmidt, S., \& Walach, H. (2004). Mindfulness-based stress reduction and health benefits: A meta-analysis. Journal of Psychosomatic Research, 57(1), 35-43.

Guitar, B. (2006). Stuttering: An integrated approach to its nature and treatment (3rd ed.). Baltimore: Lippincott Williams \& Wilkins.

Gupta, S. K. (2015). Mindfulness-based cognitive therapy in early adolescents who stutter. Delhi Psychiatry Journal, 18(2), 452-455.

Hancock, K., \& Craig, A. (1998). Predictors of stuttering relapse one year following treatment for children aged 9 to 14 years. Journal of Fluency Disorders, 23(1), 31-48.

Hayes, S. C., Luoma, J. B., Bond, F. W., Masuda, A., \& Lillis, J. (2006). Acceptance and commitment therapy: Model, processes and outcomes. Behaviour Research and Therapy, 44(1), 1-25.

Jones, M., Onslow, M., Packman, A., Williams, S., Ormond, T., Schwarz, I., \& Gebski, V. (2005). Randomised controlled trial of the Lidcombe programme of early stuttering intervention. British Medical Journal, 331(7518), 659-661.

Kabat-Zinn, J. (1994). Wherever you go, there you are: Mindfulness meditation in everyday life. New York: Hyperion.

Kabat-Zinn, J. (2003). Mindfulness-based interventions in context: Past, present, and future. Clinical Psychology: Science and Practice, 10(2), 144-156.

Kraaimaat, F. W., Vanryckeghem, M., \& Van Dam-Baggen, R. (2002). Stuttering and social anxiety. Journal of Fluency Disorders, 27(4), 319-331.

Lau, M. A., Bishop, S. R., Segal, Z. V., Buis, T., Anderson, N. D., Carlson, L., ... \& Devins, G. (2006). The Toronto mindfulness scale: Development and validation. Journal of Clinical Psychology, 62(12), 1445-1467.

Linehan, M. (1993). Cognitive-behavioral treatment of borderline personality disorder. New York: Guildford Press. 


\section{Cognitive Behavior Therapy and Mindfulness Training in the Treatment of Adults Who Stutter}

Menzies, R. G., O’Brian, S., Onslow, M., Packman, A., St Clare, T., \& Block, S. (2008). An experimental clinical trial of a cognitive-behavior therapy package for chronic stuttering. Journal of Speech, Language, and Hearing Research, 51(6), 1451-1464.

Menzies, R. G., Onslow, M., Packman, A., \& O’Brian, S. (2009). Cognitive behavior therapy for adults who stutter: A tutorial for speech-language pathologists. Journal of Fluency Disorders, 34(3), 187-200.

Onslow, M., Jones, M., O’Brian, S., Menzies, R., \& Packman, A. (2008). Defining, identifying, and evaluating clinical trials of stuttering treatments: A tutorial for clinicians. American Journal of Speech-Language Pathology, 17(4), 401-415.

Onyeizugbo, E. U. (2011). Simplified regulated breathing treatment for an adult with stuttering: A case study. Indian Journal of Clinical Psychology, 38(1), 89-94.

Park, T., Reilly-Spong, M., \& Gross, C. R. (2013). Mindfulness: A systematic review of instruments to measure an emergent patient-reported outcome (PRO). Quality of Life Research, 22(10), 2639-2659.

Reddy, R. P., Sharma, M. P., \& Shivashankar, N. (2010). Cognitive behavior therapy for stuttering: A case series. Indian Journal of Psychological Medicine,32(1), 49-53. doi: $10.4103 / 0253-7176.70533$

Riley, G. D. (1994). Stuttering severity instrument for children and adults (3rd ed.). Austin, Texas: Pro-Ed Inc.

Rosenberg, M. (1965). Society and the adolescent self-image. Princeton, NJ: Princeton University Press.

Roth, A., \& Fonagy, P. (2005). What works for whom: A critical review of psychotherapy research (2nd ed.). London: The Guildford Press.

Segal, Z. V., Williams, J. M. G., \& Teasdale, J. D. (2002). Mindfulness-based cognitive therapy for depression: A new approach to preventing relapse. New York: Guilford Press.

Semple, R. J., Lee, J., \& Miller, L. F. (2006). Mindfulness-based cognitive therapy for children. In R. Baer (ed.). Mindfulness-based treatment approaches: Clinician's guide to evidence base and applications (pp.143-166). San Diego, CA: Elsevier.

SPSS Inc. (2008). SPSS Statistics for Windows (Version 17.0). Chicago: SPSS Inc.

Venkatesan, S. (2009). Ethical guidelines for bio behavioral research. Mysore: All India Institute of Speech and Hearing.

WHOQoL Group. (1998). Development of the World Health Organization WHOQOL-BREF quality of life assessment. Psychological Medicine, 28(03), 551-558.

Woolf, G. (1967). The assessment of stuttering as struggle, avoidance, and expectancy. International Journal of Language \& Communication Disorders, 2(2), 158171.

World Health Organization. (1993). The ICD-10 classification of mental and behavioural disorders: Diagnostic criteria for research. Geneva: World Health Organization. 


\section{Acknowledgement:}

We would like to express our sincere thanks to Dr. S. R. Savithri, Director, All India Institute of Speech and Hearing, Mysuru for permitting us to do this study. Our heartfelt gratitude to the participants in the study for their time and cooperation.

\section{Note:}

This paper has been presented during the Centenary Conference on Psychology-An International Event during October, 2015 at the University of Calcutta, Kolkata. 